\title{
Performed Protocol Deviation
}

National Cancer Institute

\section{Source}

National Cancer Institute. Performed Protocol Deviation. NCI Thesaurus. Code C93434.

A completed assessment for variation from process or procedures defined in a study protocol. 